\title{
Transformaciones y pervivencias sociales en la Armada: los requisitos de acceso de los guardiamarinas (1717-1869)*
}

\author{
Pablo Ortega-del-Cerro**
}

Recibido: 19 de noviembre de 2015 / Aceptado: 4 de mayo de 2016

\begin{abstract}
Resumen. En este trabajo se estudia la creación, desarrollo y evolución del guardiamarina español a través de los requisitos sociales exigidos desde principios del siglo XVIII hasta el segundo tercio del siglo XIX. Los objetivos son: conocer con mayor profundidad una figura fundamental de la Armada española, que todavía hoy requiere un examen exhaustivo; y, sobre todo, relacionar las transformaciones de los requerimientos de los candidatos con los debates sociales existentes en España durante estos dos siglos. Veremos que el denominado tránsito de la sociedad de los estamentos a la sociedad de clases, o el paso de una sociedad de principios adscriptivos a otra en base a criterios adquiridos, no se produce linealmente; los cambios e inercias no estuvieron exentos de contradicciones y discordancias, por eso analizamos el guardiamarina utilizando diversas variables relacionalmente.
\end{abstract}

Palabras clave: cambio social; jerarquía social; nobleza; élites; guardiamarina; Real Armada.

\section{[en] Social Transformations and Survivals in the Spanish Navy: The Midshipmen's Access Requirements (1717-1869)}

\begin{abstract}
This work studies the creation, development and evolution of the Spanish midshipmen, through their requirements, from the early 18 th century to the second third of the 19 th century. The aims are: to know deeply an essential post in the Navy -naval cadet- that still requires an exhaustive review; and, primarily, to link the transformations of the candidates' requirements to the social debates which were proposed in Spain during this two centuries. The so-called transition from the estates society to the class society, or the step from a society of inheriting criteria to a society based on achieving variables, did not occur linearly; changes and inertia went hand in hand with contradictions and conflicts, thus in this paper the Spanish midshipmen are analysed by several relationally variables.
\end{abstract}

Keywords: Social Change; Social Hierarchy; Nobility; Elites; Midshipman; Spanish Navy.

Sumario. 1. Introducción. 2. Creación y configuración del guardiamarina (1717-1748). 3. Consolidación y fortalecimiento del cuerpo (1748-1805). 4. Transformaciones y reacciones en tiempos abruptos (1805-1840). 5. Adaptación del guardiamarina a la sociedad burguesa (1840-1869). 6. Conclusiones.

Cómo citar: Ortega-del-Cerro, P. (2016), Transformaciones y pervivencias sociales en la Armada: los requisitos de acceso de los guardiamarinas (1717-1869), en Cuadernos de Historia Moderna 41(1), 147-168.

\footnotetext{
* Este trabajo forma parte del proyecto de investigación "Familias e individuos. Patrones de modernidad y cambio social (siglos XVI-XXI)", financiado por el Ministerio de Economía y Competitividad. Proyecto coordinado HAR2013-48901-C6-1-R.

** Universidad de Murcia. pablo.ortega1@um.es
} 


\section{Introducción}

El intervalo cronológico que va desde principios del siglo XVIII hasta el segundo tercio del XIX nos pone frente a un periodo de fuertes transformaciones en todos los órdenes. Además del paso del Antiguo al Nuevo Régimen, hablando en términos políticos, se produce una transformación social que ha sido bautizada de numerosas formas. Teóricamente partimos de una sociedad inspirada en la desigualdad jurídica entre privilegiados y no privilegiados, amparada en criterios adscriptivos como variables de jerarquización social, como son los estamentos, la sangre, el linaje y la casa; y llegamos a una sociedad que se promulga en base a las clases, el conocimiento, el mérito, la preparación, la riqueza, el individuo o, lo que es sinónimo, en elementos adquiridos. Esta afirmación puede caer, y de hecho generalmente así ocurre, en dos errores fundamentales: una valoración lineal y de tintes evolucionistas del cambio social, y la reducción y simplificación de muchas de las variables que conforman las estructuras y realidades sociales ${ }^{1}$.

El cambio social, debido a su gran complejidad, es un objeto difícilmente abarcable desde una sola disciplina científica, razón por la cual diversas ciencias sociales han desarrollado numerosos enfoques y estrategias para su análisis y comprensión. Una de las propuestas historiográficas más interesantes al respecto ha sido la que ha focalizado su atención en el binomio guerra-sociedad pues, como señala André Corvisier, la guerra como hecho social complejo y multidimensional fue, durante la Edad Moderna, uno de los principales motores de transformación social ${ }^{2}$. La Marina de guerra también se ha postulado como un válido camino para estudiar el cambio social, tal y como demuestran algunas aportaciones de la historiografía inglesa y francesa, así como de la sociología. Sobresalen especialmente los estudios de los oficiales y cadetes navales - midshipmen y gardes de la marine-, porque han permitido indagar la importancia de la educación, la formación y la preparación ${ }^{3}$, la transformación de los criterios que construyen las jerarquías sociales ${ }^{4}$, o las tensiones entre categorías y grupos sociales 5 . A todo ello se une la sugerente propuesta de Norbert Elias quien, desde su teoría del proceso de civilización, analizó la transformación de la sociedad inglesa a través de la profesionalización de los oficiales navales y la progresiva institucionalización del midshipman ${ }^{6}$.

$1 \quad$ Algunas reflexiones claves al respecto: Nisbet, R.: Social Change and History: Aspects of the Western Theory of Development, Londres, Oxford University Press, 1977; DonaTI, P.: "Pensamiento sociológico y cambio social: hacia una teoría relacional", Revista Española de Investigaciones Sociológicas, 63 (1993), pp. 29-51; BURKE, P.: Historia y teoría social, Buenos Aires-Madrid, Amorrortu editores, 2007; UríA, J.: "La historia social hoy", Historia Social, 60 (2008), pp. 233-248.

2 Corvisier, A.: "Reflexiones sobre la guerra y el cambio social en Europa Occidental", en Para comprender el cambio social. Enfoques teóricos y perspectivas historiográficas. V Conversaciones Internacionales de Historia, Pamplona, Universidad de Navarra, 1997, pp. 211-224.

3 Julia, D.: "La formation des officiers de marine dans le seconde moitié du XVIIIe siècle: des gardes de la marine aux écoles d'Alès et de Vanne”, en Dupuy, R., Frélaut, B., Juliá, D. y Le Goff, T. J.: Vannes aux débuts de la Révolution, Vannes, Les Amis de Vannes, 1989, pp. 57-124; Vergé-Franceschi, M.: Marine et éducation sous l'Ancien Régime, Paris, Editions du Centre national de la recherche scientifique, 1991.

4 DANDEker, Ch.: "From Patronage to Bureaucratic Control: the Case of Naval Officer in English Society, 17801850", British Journal of Sociology, 29, 3 (1978), pp. 300-320; HunTer, M. C.: A Society of Gentlemen: Midshipmen at the US Naval Academy, 1845-1861, Annapolis, Naval Institute Press, 2010.

5 CAvell, S.: Midshipmen and Quarterdeck Boys in the British Navy, 1771-1831, Woodbridge, Boydell Press, 2012.

6 Elias, N.: The Genesis of the Naval Profession, Dublin, University College Dublin Press, 2007. 
En lo referente a la Monarquía española, uno de los hitos principales del proceso de reformas que los primeros Borbones pusieron en marcha fue la reorganización del sistema naval ${ }^{7}$. Más allá de la unificación de las escuadras, la política de construcción de buques o la creación de arsenales, sobresale el hecho de haber creado un cuerpo único de oficiales, el llamado Cuerpo General de la Armada. En palabras de J.P. Merino "el siglo XVIII presenta la profesionalización definitiva de los oficiales de la armada... Con una formación académica, estos hombres, procedentes de los estratos medios y bajos de la nobleza, sustituyeron progresiva e irreversiblemente a los antiguos oficiales extraídos de la marina mercante y de los corsarios" ${ }^{\text {. Este }}$ mismo autor señala que para entender este proceso es necesario resaltar la figura del cadete naval, o guardiamarina, que nació en 1717 y se mantuvo -con algunos periodos de vacilación- hasta el preludio del Sexenio Democrático a través de diferentes centros?.

Aunque hay trabajos que nos han introducido en el origen, papel y significado del guardiamarina ${ }^{10}$, todavía hoy es una figura que necesita un examen más exhaustivo y detallado. Teniendo en cuenta las particulares características que se imprimieron desde su nacimiento, constituye un interesante sendero para ahondar sobre diversas cuestiones del cambio social. La Compañía de Guardias Marinas fue creada como un cuerpo de élite en un doble sentido: primero, porque estaba reservado únicamente a la nobleza; y segundo, porque sus miembros estaban obligados a formarse y prepararse como ningún otro cuerpo militar ${ }^{11}$. Ambas acepciones hacen referencia a valores vertebrales de dos modelos teóricos de sociedades diferentes: uno basado en el nacimiento y la adscripción, y el otro en el mérito personal y la adquisición. Sin embargo, lo realmente interesante no es intentar discernir la decadencia de uno y la emergencia de otro -como arquetipos sociales deben interpretarse como tal, como proyecciones-, sino indagar qué relación existía entre los elementos de ambos, cómo se construyen y transforman por las prácticas sociales, o cómo repercutían en la sociedad.

Para un repaso general al respecto véase CEPEDA Gómez, J.: "La historiografía sobre la Marina en los siglos XVIII y XIX", Revista de Historia Naval, 56 (2008), pp. 123-146.

8 Merino Navarro, J. P.: La Armada española en el siglo XVIII, Madrid, Fundación Universitaria Española, 1981 , p. 34.

9 Real Academia de Guardias Marinas (1717-1825), Real y Militar Colegio de Caballeros Guardias Marinas (1825-1828) y el Colegio Naval Militar (1845-1868). Al respecto véase BlanCA CARLIER, J. M.: "La Escuela Naval Militar, su origen histórico", Revista de Historia Naval, 32 (1991), pp. 11-44.

10 Alía Plana, J. M.: La Enseñanza de la Náutica en la Armada española (1717-1820), tesis doctoral leída en la Universidad Nacional de Educación a Distancia, 2001, dirigida por la Dra. Paloma Pernil Alarcón; Hervás AviLÉs, R. M.: "La formación académica en la Armada: Guardiamarinas americanos en Cartagena, 1777-1824", Revista de Historia Naval, 49 (1995), pp. 105-112; O’Donnell y Duque De Estrada, H.: "La formación del oficial en el siglo XVIII. El marino ilustrado", en De la Paz de París a Trafalgar (1763-1805). Génesis de la España Contemporánea: VII Jornadas de Historia Militar, Madrid, Ministerio de Defensa, 2002, pp. 43-68; Martín García, A.: "Educación y cultura en El Ferrol ilustrado: la Academia de Guardias Marinas", en Bravo Caro, J. J. y Villas Tinoco, S. (eds.): Tradición versus innovación en la España Moderna, Málaga, Universidad de Málaga, vol. II, pp. 849-868; Sánchez BAEnA, J. J.: “Aspirantes a oficiales de la Real Armada en la Academia ilustrada del Mediterráneo: esplendor y crisis (1776-1824), en García Hurtado, M. R. (ed.): $L a$ Armada española en el siglo XVIII. Ciencia, hombres y barcos. Madrid, Sílex Universidad, 2012, pp. 329-362.

11 Solamente los cuerpos de ingenieros y artilleros del Ejército tienen unas exigencias parecidas, pero su proceso de institucionalización fue menos acusado y más tardío: CAPEl, H., SÁnchez, J. E. y Moncada O.: De Palas a Minerva: la formación cientifica y la estructura institucional de los ingenieros militares en el siglo XVIII, Barcelona, Serbal, 1988; Herrero Fernández-QuesadA, M.D.: La enseñanza militar ilustrada: El Real Colegio de Artillería de Segovia, Segovia, Academia de Artillería, 1990. 
El objetivo de este trabajo es analizar la reglamentación que funda y conforma el cuerpo de guardiamarinas desde 1717 hasta 1869, centrándonos especialmente en los requisitos sociales y en el perfil del cadete naval que fue desarrollándose. La razón de esta cronología responde a que este periodo de ciento cincuenta años es lo suficientemente amplio como para indagar y evaluar los aspectos del cambio social que queremos poner el relieve. Póngase como ejemplo ilustrativo que durante este intervalo eran exigidas unas pruebas que demostrasen la distinción social de las familias -de nobleza y limpieza de sangre hasta 1836 , y de legitimidad y limpieza de sangre hasta 1865-, lo cual es indicativo de la fuerza de valores sociales amparados en la adscripción ${ }^{12}$. De este modo queremos examinar la evolución, relación y preponderancia de los diferentes criterios exigidos en cada época, y estudiarlos conjuntamente con algunos de los principales debates sociales.

Finalmente, no está de más subrayar que el objeto que tratamos son los criterios exigidos a los guardiamarinas, y no a los oficiales de la Armada. Estos últimos eran reclutados fundamentalmente desde las Academias de Guardias Marinas, pero también los había que procedían del cuerpo de pilotos, aventureros, caballeros de la Orden de San Juan, etc. Tampoco se puede olvidar que las fuentes sobre las que trabajamos hacen referencia a las normativas y los discursos, y por tanto son una parte de la realidad que no siempre es coincidente con las prácticas y los hábitos empleados.

\section{Creación y configuración del guardiamarina (1717-1748)}

Los antecedentes del guardiamarina español se pueden encontrar en los alumnos del Colegio de Pilotos de San Telmo de Sevilla, los cadetes de la Escuadra de Galeras - llamados guardaestandartes - o en los sujetos que marchaban a escuelas navales extranjeras ${ }^{13}$. A ello cabe añadir la interpretación generalizada de que el precedente de referencia para España fue la Compañía francesa de Guardias Marinas, creada por Colbert en 1683. Sea como fuere, el texto germinal data de $1718^{14}$-aunque la Academia ya estaba en marcha desde 1717-, está rubricado por José Patiño, e instituye un cadete naval noble y servidor. A decir verdad este binomio no tiene nada de nuevo en el lenguaje social del momento pero, si analizamos el contexto de reformas que Felipe $\mathrm{V}$ está promoviendo, y la propia naturaleza de esta institución formativa, podemos contemplar rasgos diferenciadores con la época anterior.

El carácter nobiliario del cuerpo es determinante, pues será el rasgo aparentemente predominante durante toda la centuria ${ }^{15}$. Contemplando lo que señalaba Patiño, "Biendo la nobleza de España sin carrera, poco aplicada a seguir ninguna, y

12 Tesis clásica promulgada por MAYER, A. J.: La persistencia del Antiguo Régimen: Europa hasta la Gran Guerra, Madrid, Alianza Editorial, 1986.

13 Blanca Carlier, op. cit (nota 9), p. 11. Véase también Blanco NúÑEz, J. M.: "La Real Armada”, en O’DonNell y Duque de Estrada, H. (dir.) y Iglesias Cano, M. C. (coord.): Historia militar de España. III. Edad Moderna, III. Los Borbones, Madrid, Laberinto y Ministerio de Defensa, 2014, pp. 303-324.

14 Instrucción para el gobierno, educación, enseñanza y servicio de los Guardia Marinas y las obligaciones de sus oficiales y maestros de facultades, Cádiz, 15 de abril de 1718. Archivo Museo Naval (AMN), Real Compañía de Guardias Marinas, caj. 440, ms. 1181, ff. 31-57; y caj. 762, ms. 2423, ff. 1-33 y 34-75.

15 Un análisis paralelo desde la perspectiva científica, LAFUEnTE TORRALBA, A. y SELlÉS García, M.: "El proceso de institucionalización de la Academia de Guardiamarinas de Cádiz (1717-1748)”, en Echevarría ExpondA, J. y Mora Charles, M. De (coord.): Actas del III Congreso de la Sociedad Española de Historia de las Ciencias, vol. 2, San Sebastián, Editorial Guipuzcoana, 1986, pp. 153-176. 
en una crianza que no la distinguía de la plebe"16, podemos comprender cómo la movilización de la nobleza se convirtió en un objeto de gran urgencia. Por esta razón determina que "Las circunstancias que deben tener un Guardia Marina para ser asentado y admitido es la calidad de hijodalgo a el uso de España, o hixo de capitán inclusive arriba ${ }^{17}$, y la prueba deberá presentarse al mismo tiempo que el Decreto de Su Majestad"18. Este requerimiento de presentar unas pruebas de nobleza no fue exclusivo de la Armada; fue extensivo a todos los brazos armados de la Monarquía, que a comienzo del siglo XVIII también habían experimentado un fuerte proceso de reforma. A los cadetes del Ejército se les pedía que fueran hijosdalgo, lo cual constituyó el pilar fundamental para crear una institución nobiliaria ${ }^{19}$. Sin embargo, ya sea en tierra o en mar, la predilección por la nobleza no era en sentido estricto una consecuencia de la aplicación de la lógica estamental -nobleza como sinónimo de bellatores; las reformas de los Borbones buscaban al mismo tiempo perpetuar el sistema social, al reservar a la nobleza la función militar, pero también pretendían establecer importantes transformaciones. Como señala Francisco Andújar, se produce "un proceso de atracción del estamento nobiliario hacia un Ejército configurado como institución al servicio del Estado y bajo el control directo del Rey absoluto" 20 .

No se puede entender la verdadera naturaleza nobiliaria de este cuerpo sin especificar el -nuevo- concepto de servicio que comienza a desarrollarse. Durante los siglos XVI y XVII, e incluso durante parte del XVIII, el servicio de la nobleza a la Corona -señala I. A. A. Thompson- tenía un carácter fundamentalmente pecuniario, no era específico, y siempre subordinado al linaje y a la estratificación interna del estamento ${ }^{21}$. A conclusiones parecidas llega Jiménez Estrella ${ }^{22}$, quien estudia el sistema de ascensos en el Ejército de los Austrias, y que también son extensibles en gran parte a las Armadas de la Monarquía ${ }^{23}$. A lo largo de todo el siglo XVIII, y muy lentamente, el servicio irá adquiriendo un significado diferente: irá prevaleciendo la ocupación de un cargo y una función concreta, la progresiva especialidad y la necesidad de una preparación para ello; y esto, a su vez, habría que enmarcarlo en la construcción de nuevas estructuras políticas y la remodelación de las antiguas. De este modo, la relación entre nobleza y milicia se va transformando, dejando de ser una prerrogativa propia del estamento para llegar a ser una atribución que la Corona concede a la nobleza ${ }^{24}$. Además, como señala José María Imízcoz, el verdadero

16 Copia del Informe que hizo a SM el señor don José Patiño, Intendente General de Marina de España en el año 1720 sobre la fundación y progreso de la Compañía de Guardias Marinas, Cádiz, 1720. AMN, Real Compañía de Guardias Marinas, caj. 440, ms. 1181, ff. 67-73.

17 Este referencia la podemos considerar como la grieta más evidente de ese modelo nobiliario de institución, sin embargo las reglamentaciones posteriores intentarán cerrar este brecha.

18 AMN, Real Compañía de Guardias Marinas, caj. 440, ms. 1181, f. 31 (nota 14).

19 AndúJar CASTILlo, F.: Los militares en la España del siglo XVIII. Un estudio social. Granada, Universidad de Granada, 1991.

20 Ibidem, p. 122.

21 Thompson, I. A. A.: “Do ut des: la economía política del servicio en la Castilla moderna”, en EsTEBAN EsTRíNGANA, A. (coord.): Servir al rey en la Monarquía de los Austrias: medios, fines y logros del servicio al soberano en los siglos XVI y XVII, Madrid, Sílex Ediciones, 2012, pp. 284-285. Para el caso francés véase SMITH, JM.: The Culture of Merit: Nobility, Royal Service, and the Making of Absolute Monarchy in France, 1600-1789, Michigan, University of Michigan, 1996.

22 Jiménez Estrella, A.: "Mérito, calidad y experiencia: criterios volubles en la provisión de cargos militares bajo los Austrias", en Pardo Molero, J. F. y Lomas Cortés, M. (coords.): Oficiales reales. Los ministros de la Monarquía católica (siglos XVI-XVII), Valància, Universitat de València, 2012, pp. 241-264.

23 Goodman, D.: El poderío naval español. Historia de la armada española del siglo XVII, Barcelona, Ediciones Península, 1997.

24 Morales Moya, A.: "Milicia y nobleza en el siglo XVIII. Apuntes para una sociología de las armas y de la nobleza en España”, Cuadernos de Historia Moderna, 9 (1988), pp. 121-137. 
problema que late de fondo es la acuciante necesidad que tiene la nueva dinastía por captar capital humano que ponga en marcha y ejecute su programa de reformas: "administradores de carrera especializados y con notables competencias técnicas, además de un perfil político acorde con el absolutismo reformista"25.

El guardiamarina adquiere gran relevancia en el desarrollo de este nuevo concepto de servicio -y en cierto modo también de nobleza-, tanto por la fortísima vocación marítima de la Monarquía como por encarnar el modelo que habría de imponerse en el futuro. Así queda patente en los motivos de la creación de la Compañía y de la Academia en la Instrucción de 1718:

Como el principal fin de la formación, manutención y establecimiento de este Cuerpo es para que el Rey, no solo consiga avilitar la nobleza de sus Reynos y que sirva en su Marina y Ejército adornada de las ciencias y facultades de la matemática con las reglas de cantidad discreta, geometría..., sino también aptos para otras profesiones, los que por falta de robustez o inclinación no puedan seguir la profesión militar en Mar o en Tierra, se formará una Academia ${ }^{26}$.

De este modo, el cuerpo de guardiamarinas fue creado con la intención de ser el centro matriz de la renovación de la nobleza dedicada al servicio, no solamente en la guerra naval o terrestre, sino también otras funciones:

Con el fin de que este cuerpo, fundado sobre principios de estado y políticos, se ilustrase con una aparente forma y regla militar, y tuviese correspondientes estimulaciones en que se tuvo la mira no solo a que por este medio se consiguiese el fin substancial y primario de que los individuos saliesen a propósito de la navegación y la guerra... sino también el secundario de que aquellos que por falta de robustez o inclinación seguir la profesión quedasen a lo menos aptos a regentar con acierto otros qualesquiera empleos repúblicos ${ }^{27}$.

Lo realmente interesante es ver cómo en esta génesis de la renovada acepción de servicio se conjuga la pertenencia a la nobleza con la obligatoriedad de una formación científica amplia:

La congruencia de hacer una unión y concurrencia de mozedad noble que gobernada en comunidad por superiores háviles, celosos y exemplares que hicieren observar las reglas que pudieren contribuir a lo expresado, podría producir a la Corona, y al servicio del Rey, un copioso fruto. Para ello se tuvo por conveniente poner escuelas donde se pudieran aprender las ciencias y facultades de las matemáticas, la cantidad discreta, geometría, trigonometría, cosmografía, náutica, maniobra, fortificación militar, y teórica de la artillería y de la construcción ${ }^{28}$.

25 Imízcoz Beunza, J. M.: "Élites administrativas, redes cortesanas y captación de recursos en la construcción social del Estado Moderno", Trocadero, 19 (2007), p. 11.

26 AMN, Real Compañía de Guardias Marinas, caj. 440, ms. 1181, f. 35, op. cit. (nota 14).

27 AMN, Real Compañía de Guardias Marinas, caj. 440, ms. 1181, f. 69, op. cit. (nota 16).

28 Ibidem, ff. 68-69. 
Ésta era la principal diferencia con respecto al Ejército ${ }^{29}$. En infantería y caballería la educación e instrucción de sus cadetes fue un elemento secundario y $\operatorname{tardí}^{30}, \mathrm{y}$ en las armas técnicas, aunque contaron con las Academias de Barcelona y Cádiz, no tuvieron su forma más acabada hasta la segunda mitad del XVIII con el Colegio de Artillería de Segovia ${ }^{31}$. Sin embargo, la creación del guardiamarina no estuvo exenta de cierta dosis de contradicción: las expectativas puestas sobre este cadete naval ideal contrastan con los mínimos y vagos requisitos personales que se requerían, a lo que habría añadir que ni siquiera se propusieron controles exhaustivos -a diferencia de las pruebas de nobleza:

No devieran tener más ni menos de catorce a diez y seis años, deberán saber leer, y escribir, y se prohibirá el que se admitan los que tengan imperfección de el cuerpo, los que sean avitualmente enfermos, y los que por su traza sean indecentes, $o$ reconozcan incapaces de aprovechar en los estudios, o tontos ${ }^{32}$.

Más tarde, durante el Almirantazgo del infante Felipe (1737-1748), se promovieron una serie de reformas encaminadas a concretar el perfil de los guardiamarinas comenzando por una profunda revisión de la normativa de $1718^{33}$. En primer lugar se intentaron reforzar los escasos requisitos personales exigidos a los jóvenes, de tal modo que se procedió a una expulsión -siempre disimulada por el honor familiar- de los que "por inaplicación, por ineptitud o por vicios o por otros motivos no sean dignos de mantenerse en ella ni prometan con el tiempo ser buenos oficiales de marina" ${ }^{34}$. También se estableció que "estén obligados en el término de dos años... a saber, a lo menos, la aritmética, los elementos geométricos de Euclides, según se enseña en la propia Academia, las trigonometrías plana y esférica" ${ }^{35}$; y los que no fueran aptos para la vida de mar se les permitió pasar al Ejército, opción de los que no pocos se beneficiaron.

Los proyectos del Almirantazgo culminarían con las Ordenanzas de 1748, concretamente en un tratado específico para los guardiamarinas ${ }^{36}$. Si bien es cierto que no existen cambios sustanciales, sí que se pretende imprimir una mayor exhaustividad en los requisitos de acceso y en su perfil. El rasgo más destacable es que la Academia, ahora sí, debía entenderse como un centro que se dedica en exclusividad a la formación de los oficiales de la Armada, y en menor medida del Ejército: "Siendo el principal objetivo de la formación de esta Compañía, el de educar y habilitar la noble juventud de

29 Como repaso general a esta cuestión véase Bolaños Mejías, M. C.: "La profesionalización del Ejército Real", en Martínez Peñas, L. y Fernández Rodríguez, M. (coords.): El Ejército y la Armada en el Noroeste de América: Nootka y su tiempo, Madrid, Universidad Rey Juan Carlos, 2011, pp. 251-272.

30 Andújar Castillo, F.: "La educación de los militares en la España del siglo XVIII”, Chronica Nova, 19 (1991), pp. 31-55.

31 Herrero Fernández-Quesada, M. D.: "La formación de los militares en el siglo XVIII. El Colegio de Artilleros de Segovia o la creación de un modelo", en Imízcoz, J. M. y Chaparro, A. (eds.): Educación, redes y producción de élites en el siglo XVIII, Madrid, Sílex Universidad, 2013, pp. 317-337.

32 AMN, Real Compañía de Guardias Marinas, caj. 440, ms. 1181, f. 34, op. cit. (nota 14).

33 Dictamen del Brigadier de los Exercitos y Teniente de la Compañía de Guardias Marinas José Marín, Cádiz, 29 de junio de 1737. AMN, Real Compañía de Guardias Marinas, caj. 762, ms. 2423, ff. 90-101.

34 Orden del Infante Almirante don Felipe relativa al número y calidades de los Guardias Marinas que están en la Compañía, 1739, Archivo General de Simancas (AGS), Secretaría de Marina, leg. 95, s. fol.

35 Ibidem.

36 Ordenanzas de Su Majestad para el gobierno militar, político y económico de Su Armada Naval. Parte Segunda. Que contiene los Asuntos pertenecientes a los cuerpos militares de la Armada, tratado séptimo, "De la Compañía de Guardias Marinas", título segundo, "De las circunstancias que han de concurrir en los que se admitan por cadetes en la Compañía de Guardias Marinas”, Madrid, Imprenta Juan de Zúñiga, 1748. 
mis Reynos en las ciencias, y facultades más útiles al servicio de la Armada, y al de los Ejércitos, si por defecto de inclinación o robustez no puede alguno seguir el de la Mar"37. Deja de tener, por tanto, esa pretensión de ser un centro donde la nobleza recibiera una formación básica para pasar al servicio en otras ramas, hecho que coincide con la puesta en marcha del Real Seminario de Nobles de Madrid que pasaría a cumplir esa función ${ }^{38}$.

También se delimita con mayor claridad la nobleza de los aspirantes y la importancia capital de este aspecto ${ }^{39}$, ya que todos ellos deben "ser Cavallero Hijodalgo notorio conforme à Leyes de mis Reynos" ${ }^{40}$. Se tenía que notificar la nobleza a la Secretaria de Marina al tiempo que se pide la plaza, se concretan las pruebas que han de presentarse y se regulan las inspecciones que el capitán de la Compañía tenía que llevar a cabo. Respecto a las cualidades personales de los aspirantes, poco se modifica respecto a la normativa anterior. Era necesario estar entre los catorce y dieciocho años de edad, saber leer y escribir, y se prohíbe el acceso de cualquiera que tuviera imperfección corporal o falta de robustez, "no sea capaz de aprovechamiento de los estudios", o que fuera "poco propio para las funciones del Servicio"41. La única salvedad es que, siguiendo criterios de "una cuidadosa educación, viveza y talento" 42 , el capitán podía admitir al aspirante que estuviera entre los doce y veinte años.

\section{Consolidación y fortalecimiento del cuerpo (1748-1805)}

La segunda mitad del siglo XVIII implicó el fortalecimiento del cuerpo de guardiamarinas a partir de las directrices fijadas en las Ordenanzas de 1748, las cuales representaban el espíritu de ese nuevo concepto de servicio a la Monarquía. En este sentido compartimos la hipótesis de José María Imízcoz, quien propone que "los sectores de la sociedad española de mayor modernidad política y cultural en el siglo XVIII serían los sectores... que participaron más intensamente en la construcción del Estado administrativo, militar, económico y cultural de aquella centuria, y especialmente en su segunda mitad"43. Sin embargo, este proceso también tenía discordancias, al menos aparentemente, pues como apunta María Victoria López-Cordón:

Existían, pues, unas necesidades para la administración y el gobierno del Estado; un cuerpo de servidores, dignificado en sus funciones y progresivamente ennoblecido que no paraba de crecer al calor de las distintas reformas; y un sistema de aprendizaje ambiguo, cuando no inapropiado, que dificultaba que la elección recayera en los mejores, cumpliendo así una máxima política antigua ${ }^{44}$.

\footnotetext{
Ibidem, art. II, p. 14.
}

38 Cuestión tratada por Francisco Aguilar Piñal, Jacques Soubeyroux y Francisco Andújar Castillo, al que hay que añadir la reciente aportación de Chaparro Sainz, A. y Artola Renedo, A.: "El entorno de los alumnos del Real Seminario de Nobles de Madrid (1727-1808). Elementos para una prosopografia relacional”, en ImízCOZ y CHAPARRO, op. cit. (nota 31) pp. 177-200.

39 Ordenanzas de Su Majestad, op. cit., (nota 36), tratado séptimo, título segundo, art. II, III, V y VI.

40 Ibidem, art. II, p. 14. Puede verse como ha desaparecido la mención explícita a los hijos de capitanes.

$41 \quad$ Ibidem, art. XI, p. 17.

$42 \quad$ Ibidem, artículo X, p. 17.

43 Imízcoz Beunza, J. M.: "Entre sí. Por una historia social de los procesos de civilización”, en García FerNÁNDEZ, M. y ChaCón JimÉnez, F. (dirs.): Ciudadanos y familias. Individuo e identidad sociocultural hispana (siglos XVII-XIX), Valladolid, Ediciones Universidad de Valladolid, 2014 p. 135.

44 López-Cordón Cortezo, M. ${ }^{a}$ V.: "La cultura del mérito a finales del siglo XVIII: servicio, aprendizaje y lealtad en la administración borbónica", en PÉrez SARrión, G. (ed.): Más estado y más mercado: absolutismo y economía en la España del siglo XVIII, Madrid, Sílex Ediciones, 2011, p. 84. 
En esta intersección los guardiamarinas pueden arrojar luz que nos permita comprender la idiosincrasia del periodo. Ilustrativas son las palabras que José Mazarredo pronunció en un discurso ante los jóvenes cadetes donde les recordaba que estaban allí "para que sean útiles en su servicio [del Rey], ilustren el Estado y aumenten los blasones de sus familias" ${ }^{45}$. Debemos atender a esta mención de utilidad, preparación, nobleza y servicio al Estado Real, pues no solo sintetiza el modelo que progresivamente se va cimentando ${ }^{46}$, sino porque atestigua que el guardiamarina es uno de los casos que mejor representa la confluencia de todos los elementos. En primer lugar, la nobleza de los aspirantes permaneció durante este periodo como una de las cuestiones centrales. Era un tema que preocupaba, y mucho, tanto a la Secretaría de Marina como a la propia Armada; ambas instituciones compartían su interés por robustecer el prestigio social de la Compañía de Guardias Marinas, y ello pasaba obligatoriamente por acreditar los distinguidos orígenes de los aspirantes. Por ejemplo, en 1753, Julián de Arriaga pide que se eximan de las pruebas de nobleza a los caballeros de las Órdenes Militares, porque a su entender era "repugnante que se les obligue a la formalidad de una justificación de su nobleza, practicada a propio pedimento ante las justicias de sus domicilios, dándose assi más valor a tan sencilla información, que a las que preceden al ponerse el hábito en cualquiera de las militares órdenes" ${ }^{\prime 4}$. El celo sobre la nobleza del cuerpo queda patente igualmente cuando se cierra una de las grietas más evidentes al requerimiento nobiliario. Los hijos de los militares, desde teniente coronel o capitán de fragata en adelante, estaban exentos de presentar las pruebas completas, y solo era necesaria la fe de bautismo y la patente del padre. Por tanto, la nobleza de la madre, y de su línea, quedaba ignorada ${ }^{48}$. La situación cambia en 1784 cuando se obliga en estos casos a presentar las pruebas de nobleza por línea materna ${ }^{49}$ cuando el padre fuera brigadier, coronel o teniente coronel ${ }^{50}$.

Se llegaron a imprimir durante la segunda mitad del setecientos hasta tres folletos distintos, cada cual más completo, donde se especificaban las circunstancias y los procedimientos que se debían seguir para pedir la plaza de guardiamarina y comprobar la nobleza ${ }^{51}$. Todo ello culmina en 1792 cuando se redacta definitivamente una instrucción dirigida a los capitanes de las Compañías sobre las pruebas de nobleza

45 Copia de cinco discursos de Mazarredo a los guardiamarinas en el periodo que dirige la Compañía, s. fol. AMN, Colección Mazarredo, caj. 738, ms. 2380, f. 7.

46 Calvo Maturana, A.: Cuando manden los que obedecen. La clase politica e intelectual de la España preliberal (1780-1808), Madrid, Parcial Pons, 2013.

47 Carta de don Julián de Arriaga a la Secretaría de Marina, Cádiz, 1753, AGS, Secretaría de Marina, leg. 95, s. fol.

48 Cuestión que quedaba posiblemente solucionada por la obligatoriedad de todos los oficiales de pedir licencia de matrimonio, en la cual se dictaminaba la idoneidad (y nobleza) de la esposa.

49 Este hecho evidencia la meticulosidad del asunto, y más aún si tenemos en cuento que los oficiales del Ejército así como de la Armada estaban obligados a pedir licencia para el matrimonio.

50 Aclaración de varios puntos de Ordenanza y otros no expresado en ella para el régimen del Cuerpo de Guardias Marinas, San Lorenzo, 8 de octubre de 1784, Archivo General de la Marina ‘Álvaro de Bazán’(AGMAB), Real Compañía de Guardias Marinas, leg. 720, s. fol.

51 Circunstancias que han de concurrir en los pretendientes à plazas de Guardias-Marinas, y documentos que deben presentar assi en la Corte, como en Cádiz, donde se halla establecida la Compañía; Extracto de los papeles, requisitos y circunstancias con que el pretendiente á plaza de Guardias Marina, debe presentarse al Oficial que mande aquel Cuerpo, para que le dirija con todo lo expresado a los Oficios principales de Marina a fin de que le forme asiento, no hallando ningún reparo en los propios papeles; conforme uno, y otro a la Real Ordenanza de la misma Marina, publicada en noviembre de 1749 y adicción a esta por Real Orden de 18 de diciembre de 1753; Instrucción de las circunstancias que han de concurrir en los que se admiten para Cadetes de la Compañía de Cavalleros Guardias Marinas, y de las justificaciones que deben presentar para acreditarlas, según Real Ordenanza de Marina publicada en Noviembre de 1749 y sus adicciones. AGS, Secretaría de Marina, Guardias Marinas, leg. 96, s. fol. 
que los guardiamarinas deberían presentar: "Tiene dos partes: una testimonial y otra instrumental o documental; ambas indispensables porque una qualquiera de ellas sin la otra de nada sirve. La nobleza ha de ser de los cuatro troncos: dos paternos y dos maternos; y faltando en alguno de ello no puede sentarse plaza" 52 . En realidad, sobre esta cuestión, simplemente se deja por escrito lo que ya se venía haciendo de forma habitual.

El empeño por asegurar la nobleza del pretendiente va más allá de esa prueba que debía presentar el joven cuando llegaba a la Academia; se puso en marcha un sistema paralelo, y bajo la estricta vigilancia de la Secretaría de Marina, que permitía conocer con mayor fiabilidad la nobleza de los aspirantes. Cuando un pretendiente mandaba un memorial a la Corte pidiendo plaza de guardiamarina, inmediatamente después la Secretaría mandaba realizar un informe reservado sobre las circunstancias del aspirante y de su familia. De este modo, la nobleza del futuro cadete quedaba asegurada mucho antes de la inspección de las pruebas de nobleza y limpieza de sangre que el capitán de la Compañía debía realizar ${ }^{53}$. Este procedimiento fue adquiriendo gran perfección y precisión conforme avanzaron los años, e incluso se llegó a pedir gran cantidad de información: desde la actitud y talento del joven hasta la nobleza de los cuatro troncos, pasando por los servicios y méritos prestados por su familia a la Corona ${ }^{54}$. Se establece, por tanto, un doble mecanismo de comprobación de los requisitos que debían reunir los guardiamarinas - primero por parte de la Secretaría y segundo por parte del capitán de la Compañía-, pero siempre centrando su atención en la nobleza ${ }^{55}$. El control extremo sobre esta cuestión en la Armada parece diferenciarse, como ha mostrado recientemente Francisco Andújar, del comportamiento seguido en el Ejército durante ese periodo, cuando perece que se produjo cierta permeabilidad en los requisitos de los cadetes ${ }^{56}$.

Por otro lado, también se intentan fomentar y consolidar los requerimientos personales de los aspirantes, especialmente el talento, aplicación y buena conducta tanto antes como después de ingresar en la Academia. En lo que respecta estrictamente a los requisitos de acceso, comienzan a elevarse voces que promueven la necesidad de una mejor y más cuidada educación de los aspirantes -recordemos que los jóvenes solo debían saber leer y escribir-. El capitán de la Compañía de Guardias Marinas Jorge Juan señalaba, por ejemplo, que los artículos 12 y 13 de las Ordenanzas, que versan sobre la preferencia de los hijos de militares debían ser, como poco, reconsiderada:

52 Advertencia sobre las pretensiones a plaza de Guardias Marinas, y sobre las pruebas que deben de presentar todo agraciado a ella, para que pueda formarse su asiento, 1792. AMN, Real Compañía de Guardias Marinas, caj. 762, ms. 2423, ff. 102-122.

53 Los primeros casos que hemos detectado datan de 1748, concretamente las peticiones de plaza de guardiamarina de José Alderete Medina y Damián de la Fuente. AGS, Secretaría de Marina, leg. 82-B, s. fol.

54 Informe reservado del aspirante a guardiamarinas Juan Nicolás Ulloa Bertetoros, Villa de Puentedeume, 20 de junio de 1786, AGMAB, Real Compañía de Guardias Marinas, leg. 816, s. fol.

55 Ortega-del-Cerro, P.: "Familias e instituciones: el proceso de ingreso en la Academia de Guardias Marinas en la segunda mitad del siglo XVIII”, en GARcíA FERNÁNDEZ, M. (ed.): Familia, cultura material y formas de poder en la España Moderna. III Encuentro de Jóvenes Investigadores en Historia Moderna, Madrid, Fundación Historia Moderna, 2016, pp. 347-359.

56 AndúJar Castillo, F.: "El Ejército borbónico en el último tercio del siglo XVIII: permeabilidad social en una institución nobiliaria", Chronica Nova, 40 (2014), pp. 131-154. 
A los individuos que con Carta Orden del Rey se presentan en esta Academia no habiendo cavimiento para recluirlos por estar el número de Guardia Marinas completo, tengo mandado se les dé lección de un todo del mismo modo que a los Guardias pues lo que adelantaren será otro tanto veneficio para ellos y para el Real Servicio. Algunos adelantan con particularidad, otros medianamente y a algunos se les conoce no tanta afición como se debiera desear en la aplicación; esta deficiencia se hace a veces tan notable que me ha hecho desear tener facultades para privilegiar los primeros en las plazas vacantes que hubiere, y posponer los terceros, sin embargo en los artículos 12 y 13 del título 2 del tratado 7... se previene que... sean privilegiados los hijos de Oficiales y Ministros de Marinas, después los del Ejército, que a estos se sigan los de Togados y luego los de particulares. Esta regla me parece que fuera muy conveniente se siguiese solo en el caso de iguales méritos hechos en esta Academia, pero cuando se encuentra mucha disparidad, tanto en la aplicación como en los talentos y conducta, no crea que sea lo más $\operatorname{acertado}^{57}$.

Por su parte, el marqués de la Victoria comentaba que "aunque para lo que es puramente navegar, basta que los Guardias Marinas sepan pilotaje y maniobra... es visiblemente útil y aún preciso que además sean sujetos de alguna cultura en el trato de palabra y por escrito, para las ocasiones que se hallen en mando"58. Estas demandas, y otras de fines parecidos, quedan recogidas en la citada instrucción dada a los capitanes de las Compañías de 1792, donde aparece una nota que señala: "Los nobles del Reino que deseen tener para sus hijos la gracia de plaza de Guardia Marina, deben darles una cuidadosa educación, en que cultiven su talento, y aprovechen como es menester para una carrera de ciencias en que no puede haber progreso sin poseerla"59.

Cabe añadir durante este periodo un tercer elemento que, aunque no aparece en la reglamentación tan llamativamente como los otros dos anteriores, parece convertirse en crucial. La capacidad económica de los aspirantes durante la primera mitad del siglo ni siquiera quedaba reflejada entre los requisitos exigidos, pero la búsqueda del gran lustre del cuerpo obligaba a que sus miembros se mantuvieran con una decencia acorde, lo que forzó a asegurar la manutención por parte de las familias de los guardiamarinas. Ya en la comandancia de Francisco Javier Winthuysen, en la década de 1770, se ordenaba que los aspirantes "también han de asegurar a satisfacción del Comandante de la Compañía, diez pesos mensuales de asistencia"60; al mismo tiempo comenzará a ser muy común la negativa de plaza por parte de la Secretaría aduciendo que "no es destino para pobres"61. A final de siglo este criterio acabará por ser uno de los esenciales, y para ello se recomienda que los guardiamarinas "deben asegurarse las asistencias... baxo obligación de vecino abonado en la residencia... [y] ha de ser de diez pesos al mes" ${ }^{\text {. }}$.

57 Carta de Jorge Juan al Secretario de Estado y del Despacho de Marina Julián Arriaga, 1757. AGS, Secretaría de Marina, leg. 96, s. fol.

58 Copia de dos representaciones del difunto Capitán General de la Armada, el marqués de la Victoria, al Secretario de Estado y del Despacho de Marina, Julián de Arriaga, sobre aumento de la Compañía de Guardias Marinas y otros puntos, Isla de León, 18 de octubre de 1771. AGMAB, Real Compañía de Guardias Marinas, leg. 720, s. fol.

59 AMN, Real Compañía de Guardias Marinas, caj. 762, ms. 2423, op. cit. (nota 52).

60 AGS, Secretaría de Marina, leg. 96, op. cit. (nota 51).

${ }_{61}$ Instancia de Narcisa Castillo Negrete pidiendo plaza de guardiamarina para sus hermanos Salvador y Félix, Isla de León, 3 de septiembre de 1773. AGS, Secretaría de Marina, leg. 89, s. fol.

62 Noticias de las circunstancias necesarias para solicitar del Rey la gracia de plaza de Guardia Marina y ser admitido, 1792. AGMAB, Real Compañía de Guardias Marinas, leg. 726, s. fol. 
El afán que se puso en el fortalecimiento del cuerpo de guardiamarinas durante esta segunda mitad de siglo experimentó algunos reveses en los años finales del siglo y el inicio del XIX. Bien es cierto que no existen cambios formales en la reglamentación, pues las Ordenanzas de 1793 no tratan sobre la Compañía, pero sí emergió un intenso clima de debate. Muestra de ello es el Proyecto de Ordenanza para el gobierno de las Compañias de Guardias Marinas de 1804. Aunque no fue aprobado, y por tanto nunca entró en vigor, sí que nos permite examinar algunos de los debates que subyacen en este periodo. El rasgo más sobresaliente, el cual inunda todo el texto, es la conciencia de estar viviendo un periodo convulso:

Por quanto el trascurso de muchos años y las vicisitudes políticas de los tiempos, habiendo causado singulares trastornos en el cuerpo de mi Armada Naval han traído la necesidad de mudar el orden general de su establecimiento... como entre ellas sea el de mi Real Cuerpo de Guardias Marinas, el que con más especialidad requiere ser arreglado, sobre tal convicción depare a la Marina una juventud experimentada, ilustrada, capaz de proveerla de dignos Gefes y Generales; a la Nobleza un objeto correspondiente de sus ocupaciones y pensamientos; y al Estado en esta ilustre clase de sus hijos el principal servicio de prosperidad y grandeza ${ }^{63}$.

Comprobamos que los ejes fomentados durante la segunda mitad del siglo XVIII, los que formaban el nuevo concepto de servicio, se habían consolidado. Primeramente, el ennoblecimiento del cuerpo se sigue haciendo patente en gran parte del articulado, pues se constituye como una Compañía para la "Juventud ilustre de mi Monarquía de que debe componerse, se aseguren en sus costumbres, ciencia, de dignidad y grandeza de mi Armada y el bien de mis Estados"; se siguen exigiendo pruebas de "limpieza y nobleza de sangre" a todos los aspirantes, y los hijos de oficiales del Ejército y de la Armada deberán demostrar igualmente su nobleza por parte materna ${ }^{64}$. En segundo lugar, se acentúa la necesidad de una instrucción previa de los aspirantes:

Todo pretendiente para ser admitido, ha de saber sin dispensa leer y escribir correctamente, y estar instruido a fundamento en doctrina cristiana y ser examinado de ello; sirviendo de recomendación a un agraciado para ser preferido a otros de su propia clase el mayor cultivo de su entendimiento, en especial quando la ilustración verse sobre puntos interesantes al más sólido y rápido progreso de los estudios de la Marina ${ }^{65}$.

Por otro lado, existen pequeñas novedades, aunque cualitativamente muy relevantes, que plasman la idiosincrasia de una época percibida como convulsa y extraordinaria. Los años finales del XVIII y los primeros del XIX, entre los muchos calificativos que pudieran tener, suelen ser denominados como un tiempo de héroes ${ }^{66}$, y esto también se muestra en el proyecto del nuevo reglamento en el cual se recoge

\footnotetext{
63 Proyecto de Ordenanza para el Gobierno de las Compañías de Guardias Marinas, 1804. AMN, Real Compañía de Guardias Marinas, caj. 803, ms. 2490.

${ }^{64}$ Ibidem, título primero, art. I y II, pp. 2-3; título séptimo, art. IX, X y XIII, pp. 175-182.

65 Ibidem, título séptimo, artículo VII, pp. 173-174.

${ }_{66}$ Chust, M. y Mingue, V. (eds.): La construcción del héroe en España y México (1789-1847), Valencia, Publicaciones Universidad de Valencia, 2003.
} 
que: "no por eso es mi Real Ánimo dejar de que sea atendida por semejantes términos la memoria de los difuntos oficiales beneméritos de mi Armada, y con especialidad de los que han derramado su sangre por mi servicio; pues concederá a sus pobres hijos huérfanos el amparo de mis auxilios para que sean admitidos y sustentados"67. Estos aspirantes hubieran representando la primera fisura formalmente recogida en la reglamentación pues, aunque no fueran nobles, podían haber pedido la plaza con los mismos derechos que los demás ${ }^{68}$.

\section{Transformaciones y reacciones en tiempos abruptos (1805-1840)}

El primer tercio del siglo XIX es un tiempo de agitación, convulsión y excitación, no solo a los ojos de los historiadores, sino especialmente a los de sus contemporáneos. Se bascula entre una sensación de ruptura, de haber dejado atrás una etapa histórica, y al mismo tiempo de cambio, de realidades emergentes diferentes; es un periodo de debate con respecto al siglo anterior y afloran cuestiones que anteriormente eran latentes o estaban en cierto modo silenciadas.

En la Armada también se respira este clima y se produce un cuestionamiento general. "¿Qual puede haber sido el motivo de tan grande mudanza en la Armada española?"69, se preguntaba un "oficial aplicado" de la Marina en 1803. Entre los múltiples interrogantes que se plantean destaca el de las condiciones de acceso de los guardiamarinas y el plan de estudios vigente ${ }^{70}$. También despunta, sobre cualquier otro aspecto, la negativa valoración de la segunda mitad del siglo XVIII. Frente a una imagen de esplendor del cuerpo, de su preparación y su distinción como una carrera nobiliaria y de ciencias, ahora se nos presenta como una época de excesos, de irregularidades y de ser la causante de los desastres navales habidos y por haber, tal y como ocurrió en el Ejército ${ }^{71}$. El mismo oficial anónimo llega a afirmar que:

Se ha creído que para disponer de un joven oficial bastaba que presentase sus papeles nobles de hidalguía y enseñarle la matemática... Los partidarios de la nobleza todo lo esperan de ella... separémonos de varias ilusiones: dexemos la suposición de que la sangre inspira las inclinaciones... Dos son las qualidades que concurren a inclinar a un hombre a obrar bien... una es la consideración de las hechas por sus primogénitos; la otra la impresión que hacen en su corazón las máximas que le han inspirado en su educación ${ }^{72}$.

Afirmaciones como éstas muestran cómo el renovado concepto de servicio dieciochesco estaba entrando en crisis, pues uno de sus pilares -la preponderancia de la nobleza en la ocupación de los altos puestos militares, administrativos...- se estaba

${ }_{67}$ AMN, Real Compañía de Guardias Marinas, caj. 803, ms. 2490, op. cit. (nota 63), título primero, artículo III, p. 4.

68 Ibidem, título séptimo, artículo XIV, pp. 182-183.

69 Reflexiones de un oficial aplicado sobre el estado de la Marina y mejoras que es necesario hacer en ella, 1803, AMN, caj. 253, ms. 473, ff. 94-108.

70 Sobre los cambios y críticas en la vida académica, véase Alía PlanA, op. cit. (nota 10), pp. 169 y ss.

71 CEPeda Gómez, J.: El Ejército español en la política española (1787-1843), Madrid, Fundación Universitaria Española, 1990, pp. 155 y ss.

72 AMN, caj. 253, ms. 473, op. cit. (nota 69). 
cuestionando. Además, cabe advertir que los parámetros en los que se encuadran estos debates cambian sin solución de continuidad. Una ilustración al respecto lo proporciona la propuesta de ese "oficial aplicado" para los requisitos de los guardiamarinas que, aunque no dista mucho de las anteriores, presenta una diferencia crucial. El joven aspirante debería presentarse en primer lugar ante el director del Colegio, y éste debería indagar y tomar nota de las cualidades y talento del aspirante, así como comprobar que sabe leer y escribir correctamente. Una vez confirmada su idoneidad, y sólo después de su constatación, se tomarían las diligencias pertinentes para conocer su verdadera nobleza y, finalmente, darle asiento. Se produce aquí el viraje clave, en su mínima expresión, de los valores sociales.

Los acontecimientos que siguen en estos años son conocidos: invasión francesa, guerra y reunión de Cortes. Éstas últimas son las que, en el año de 1811, promulgan la supresión de las pruebas de nobleza para acceder a cualquier Colegio y Academia Militar, lo que desencadenó un bucle de incertidumbre y recelos ${ }^{73}$. En el mes de agosto de ese mismo año José Bermúdez, comandante general de las Academias de Guardias Marinas, manda una carta a José Vázquez de Figueroa, Secretario de Marina, para que le aclarara algunas dudas sobre la medida tomada. Especialmente llamativo es el énfasis que le pone a la posibilidad de admitir aspirantes que no perteneciesen a la nobleza:

[i] deberán ser admitidos los hijos de mercaderes por menor así de texidos y ropas como de géneros comestibles, y de los que exerzan los demás oficios mecánicos [?], pues podrá suceder que en este caso no pueda optar el hijo de algún sujeto benemérito y decente a tal gracia por falta de asistencia, quando la disfruta en los de aquella clase, que siendo tal vez del origen más obscuro, qual otra sanguijuela, han engordado y enriquecido a costa de la sangre del público... [ï] han de tener el tratamiento de don [?] pues me parece repugnante que no habiendo contraído mérito alguno al tiempo de sentar plaza el pretendiente goce desde luego un distintivo de que tal vez su padre no podrá usar ${ }^{74}$.

Los posicionamientos ante los nuevos tiempos que parecían avecindarse fluctuaron entre el estímulo de unos, la aceptación por inercia de otros, o el rechazo frontal de muchos. En lo que respecta al debate sobre los requisitos de los cadetes navales, aunque una cuestión muy concreta, era generalmente utilizado como vehículo para especular sobre los temas candentes. Francisco Javier Borrull, diputado por el reino de Valencia en 1811, al exhortar sobre la necesidad de demostrar la nobleza o no en los Colegios Militares ${ }^{75}$, avisa que todo ello puede ser "motivo a muchas disensiones entre la nobleza y la plebe" "76. De hecho llega a plantear que, en el estado de excepción de ese año, se puedan crear colegios militares en cada provincia, y que en ellos

Pérez Ledesma, M.: "Las Cortes de Cádiz y la sociedad española”, Ayer, 1 (1991), pp. 167-206.

74 Carta de José Bermúdez a José Vázquez de Figueroa sobre el decreto de las Cortes Generales y Extraordinarias, Isla de León, 24 de agosto de 1811. AGMAB, Real Compañía de Guardias Marinas, leg. 722, s. f.

75 Cepeda Gómez, J.: "La creación de colegios militares durante la Guerra de Independencia”, en De DieGo, E. y Martínez Sanz, J. L. (coord.): El comienzo de la Guerra de la Independencia, Madrid, Editorial Actas, 2009, pp. 174-196.

${ }^{76}$ Discurso que escribió D. Francisco Javier Borrul Vilanova, Diputado del Reyno de Valencia, para impugnar en las Cortes (...) el dictamen de la comisión de guerra sobre admitir en los Colegios y Academias Militares y Cuerpos Privilegiados a los españoles de familias honradas, Cádiz, Imprenta de D. Antonio de Murguia,1811, p. 4. 
se admita a los hijos de familias honradas, pero siempre reservando a la nobleza los cuerpos privilegiados: "Poco importa que se haya mudado el sistema de la Nación, como la comisión asegura, porque... éste requiere el poder intermedio de la nobleza, y de las distinciones y prerrogativas correspondientes a la misma"77.

La vuelta de Fernando VII supone el regreso del requerimiento de nobleza para ser guardiamarina -a excepción del breve intervalo de 1820-1823; no obstante, ya la situación era cualitativamente distinta, pues la fuerza simbólica de la nobleza había sido fuertemente trastocada. En paralelo existen otros temas de debate sobre los requisitos de los aspirantes a guardiamarinas, aunque de una intensidad menor. Mientras seguía vigente la reglamentación de 1748 y las adicciones posteriores, numerosos oficiales alzan su voz exponiendo la penosa situación de la Marina. Algunos, como Luis Navarrete, pedían que ante el atraso en los pagos a oficiales se les diese la oportunidad de ingresar a sus hijos en la Academias ${ }^{78}$. Otros no dejaban de reclamar la necesidad de mejorar la formación de los guardiamarinas, tanto la instrucción anterior como la recibida en la Academia, y especialmente en cuestiones científicas como la astronomía, la mecánica o la artillería ${ }^{79}$.

La década de 1820 fue un periodo crucial para sociedad española, y muy especialmente para los guardiamarinas. Por un lado, cerraban las Academias de Ferrol y Cartagena en 1824 y la de Cádiz en 1825, finalizando así un modelo de institución. Por otro lado, se pone en marcha un nuevo centro, el Colegio Real y Militar de Caballeros Guardias Marinas, que, aunque tuvo una vida cortísima (1825-1828), representaba en cierto modo un nuevo arquetipo de guardiamarina. En su reglamentación aparecen los tres criterios básicos que se fraguaron durante la segunda mitad del siglo XVIII ${ }^{80}$, pero acondicionados a la realidad de principios del XIX. Primero, los requerimientos socioeconómicos adquieren una gran relevancia, y por ello se establecen las medidas necesarias para que se asistan y se mantengan económicamente a los aspirantes de forma efectiva ${ }^{81}$. "La familia del Guardia Marina, para que se le siente plaza, ha de presentar obligación bajo escritura y la consecuente fianza, de que se le asistirá puntualmente con seis reales diarios mientras subsista en el Colegio, adelantando desde luego el importe de tres meses". Segundo, ahora los requisitos individuales aparecen como preponderantes. Además de la edad -entre 13 y 18 años-, robustez y disposición, los aspirantes están obligados a "saber doctrina cristiana y escribir correctamente con regular forma de letra y principios de ortografía, y poseer también en grado suficiente los elementos de aritmética y geometría, sobre todo lo cual sufrirán el correspondiente examen por maestros a presencia de la Junta Directiva"82. Este procedimiento, que se aplicará también al recién creado

\footnotetext{
$77 \quad$ Ibidem, pp. 9-10.

78 Reflexiones de Luis Navarrete sobre los accesos de los guardiamarinas y la situación de los oficiales, Madrid, 4 de diciembre de 1817. AGMAB, Real Compañía de Guardias Marinas, leg. 723, s. fol.

79 Discurso sobre el estado defectuoso en que se halla el Cuerpo general de la Armada y modo de mejorar su constitución, empezando por la educación que se da al Cuerpo de Guardias Marinas, ¿Madrid, 1 de septiembre de 1807? AMN, caj. 253, ms. 473, ff. 64-93.

80 Proyecto de reglamento provisional sobre un nuevo sistema de educación, servicio y ascensos de los Caballeros Guardias Marinas de la Real Armada, Madrid, 11 de marzo de 1825. AGMAB, Real Compañía de Guardias Marinas, leg. 723, s. fol.

81 En similares términos se exigía en el Ejército, FERnÁNDEZ BASTARRECHE, F.: El Ejército Español en el siglo XIX, Madrid, Siglo XXI Editores, 1978, p. 107.

82 AGMAB, Real Compañía de Guardias Marinas, leg. 723, op. cit. (nota 80), título 2º, artículo 73.
} 
centro formativo del Ejército ${ }^{83}$, no solo es una reclamación de una mayor educación e instrucción de los jóvenes, sino que evidencia el avance sutil de los requisitos personales - constituidos ahora como la verdadera llave de acceso- sobre el resto. Incluso prevalecerán sobre el criterio de auto-reclutamiento: "Siendo más los pretendientes que las vacantes, se da la preferencia al más adelantando en sus estudios y en iguales circunstancias a los hijos de los Generales de Mar y Tierra, y en segundo lugar a los demás sociales del Cuerpo" 84.

Tercero, sobre la nobleza de los pretendientes, el Colegio se sigue entendiendo como una institución nobiliaria, pero apenas queda reflejado en su articulado. A la hora de precisar las pruebas simplemente se limita a decir: "los requisitos y pruebas de nobleza que se exijan serán las mismas que hasta aquí, así como también las excepciones en favor de personas privilegiadas" 85 . Hay que esperar al reglamento definitivo para conocer específicamente las circunstancias nobiliarias que deben reunir los sujetos, y los memoriales y documentos que deben presentar ${ }^{86}$, aunque se trata en realidad de una copia de las instrucciones sobre las pruebas de nobleza dadas en 1792. Finalmente, es en el año 1836 cuando se suprimen las pruebas de nobleza para el acceso a la Armada y otras instituciones militares, y es en los siguientes términos como se expresan las razones que llevan a determinar esta medida:

Mengua sería del gobierno de Su Majestad justo apreciador del mérito adquirido en los campos del honor, menoscabar los timbres y blasones que el tiempo inmemorial constituyen el patrimonio de gloria que heredamos de nuestros antepasados... [pero] la necesidad de excitar, de estimular, el valor y los talentos en ciertas carreras, a fin de reparar los atrasos causados por nuestras guerras y desastres; y el exemplo de las naciones que nos preceden en el camino de la civilización, precisan a moderar la exigencia de ciertos requisitos de hidalguía, que ... alejaban por esa leve falta, de las carreras militares y científicas a jóvenes de limpia ascendencia, hijos de padres beneméritos y llenos de talentos y esperanzas $^{87}$.

Con esta ley, y junto a otras de naturaleza similar, la sociedad dividida jurídicamente entre privilegiados y no privilegiados queda desarticulada definitivamente, dando lugar a la denominada "confusión de los estados" que tendrá una especial incidencia en el Ejército y la Armada ${ }^{88}$. Unos principios que podemos denominar "burgueses", como el dinero, el mérito individual o la preparación, y que habían ido desarrollándose durante todo el siglo XVIII, comienzan ahora a considerarse como los criterios rectores de la sociedad. No obstante, aunque es cierto que la

Reglamento para el Real Colegio General Militar que por ahora se establece en el Real Alcázar de Segovia, Madrid, Imprenta Real, 1824.

84 AGMAB, Real Compañía de Guardias Marinas, leg. 723, op. cit. (nota 80), título segundo, art. 77.

85 Ibidem, título segundo, art. 70.

${ }_{86}$ Reglamento provisional aprobado por el Rey Nuestro Señor para el Establecimiento y Gobierno del Colegio Real y Militar de Caballeros Guardias Marinas, Madrid, Imprenta Real, 1825. AMN, Real Compañía de Guardias Marinas, caj. 457, ms. 1289.

87 Borrador de la Real Orden que suprime las pruebas de nobleza, 1836. AGMAB, Real Compañía de Guardias Marinas, leg. 724, s. fol.

88 Martínez Ruiz, E.: "Nobleza y milicia: contornos y tendencias de una nueva relación (1780-1870)", en IGLESiAs CANo, M. ${ }^{a}$ C. (ed.): Nobleza y sociedad en la España Moderna II, Oviedo, Nobel, 1997, pp. 153-173. 
nobleza deja de existir como estamento, eso no significa que muchos de los valores que representaba desaparezcan, como tampoco "pierden su identidad, prestigio e influencia" 89 .

\section{Adaptación del guardiamarina a la sociedad burguesa (1840-1869)}

La sociedad burguesa es un concepto interesante para analizar el ecuador del siglo XIX ya que hace referencia a un modelo de orden social, económico y político. Los principios de libertad individual, competencia económica, mérito, capacidad personal y garantías constitucionales son algunos de los elementos más reseñables ${ }^{90}$. El término recoge los vectores principales hacia donde se dirige -hipotéticamente- la sociedad decimonónica una vez suprimido el viejo orden. Además, como señala Juan Pro, eso fue acompañado de una apertura a nuevos grupos sociales, aunque "no [de forma] indiscriminada, sino muy selectiva" $"$.

La Armada, siendo consciente de su profundo declive durante el reinado de Fernando VII y las regencias, comienza a promover proyectos de reforma que pasan por dotar de nuevo a los cadetes navales de un centro propio de formación. En sus propuestas expresan la necesidad de encarnar los nuevos valores emergentes, especialmente la preparación y el conocimiento, porque "la falta de saber de este Cuerpo, siempre ha acarreado males sin cuento... [y] es necesario dar una educación física, moral, militar y científica a los alumnos de los varios ramos que constituyen la Armada" ${ }^{92}$. Un primer proyecto de reglamento para un nuevo centro data de $1842^{93}$, que tiene muchas similitudes con el de 1825 , pero no será hasta 1844 cuando se redacte el texto definitivo que se aplicará en el Colegio Naval Militar (1845-1868) ${ }^{94}$. En su normativa podemos ver la conjugación de elementos y valores, como señaló Jesús Cruz, tanto de innovación como de continuidad ${ }^{95}$. Por un lado, los requisitos económicos de la familia acaban por ser uno de los principales a examinar $\mathrm{y}$, por eso, se exige que "antes de ser admitido, cada alumno, padre o tutor entregará al segundo teniente de la Compañía una escritura de obligación de satisfacer por semestres adelantos el importe de la asistencia... de estar asegurado con fincas de doble valor"96. La excepción a este requisito se dará a los huérfanos de oficiales de los cuerpos de la Armada que hayan muerto en combate o naufragio ${ }^{97}$.

89 Pro Ruiz, J.: "Las élites de la España liberal: clases y redes en la definición del espacio social (1808-1931)", Historia Social, 21 (1995), pp. 47-69.

90 KockA, J.: "Burguesía y sociedad burguesa en el siglo XIX. Modelos europeos y peculiaridades alemanas", en Fraderas, J. M. y Millán, J. (eds.): Las burguesías europeas del siglo XIX. Sociedad civil, política y cultural, Madrid-Valencia, Biblioteca Nueva y Universidad de Valencia, 2000, pp. 42-54.

91 Pro Ruiz, J.: "La formación de la clase política liberal en España (1833-1868)", Historia Contemporánea, 23 (2001), p. 449.

92 Informe de Miguel Moreno a Francisco Javier Ulloa, Secretario de Estado y del Despacho de Marina, Comercio y Gobernación de Ultramar, Madrid, 22 de noviembre de 1837, AGMAB, Real Compañía de Guardias Marinas, leg. 724, s. fol.

93 Proyecto de Reglamento del Colegio Naval Militar realizado por Tomás de Sortea y con el visto bueno de Roque Guruceta, Madrid, 8 de octubre de 1842. AMN, Colegio Naval Militar, caj. 448, ms. 1210.

94 Borrador del Reglamento del Colegio Naval Militar, 1844. AGMAB, Colegio Naval, leg. 822.

95 Cruz, J.: Gentlemen, Bourgeois, and Revolutionaries. Political Change and Cultural Persistence among the Spanish Dominant Groups, Cambridge University Press, 1996, pp. 205-207.

96 Reglamento para el régimen y gobierno del Colegio Naval Militar, aprobado por SM. Madrid, Imprenta Real, 1844 , art. 59.

$97 \quad$ Ibidem, art. 62. 
Los requisitos explícitamente personales parecen consolidarse pues, además de estar cada vez más delimitados, adquieren una mayor concordancia con el puesto que ocupará el aspirante. Ejemplos son las certificaciones médicas -de robustez y aptitud física-, de conducta y de instrucción básica, pero sobre todo la obligatoriedad de aprobar un examen que comprendía "leer y escribir correctamente..., doctrina cristiana e historia sagrada, gramática castellana, nociones de historia general, y la particular de España, elementos de aritmética y geografía general, de dibujo, leer y traducir francés o inglés" ${ }^{\prime 98}$. Sin embargo, este aparente triunfo de los requisitos individuales se contrapone con criterios heredados que continúan teniendo gran fuerza, en concreto los familiares y profesionales. Esto viene dado porque se generaliza un mecanismo de cierre social a través de listas cerradas. Los aspirantes, antes de realizar el examen, se organizaban en tres escalas separadas: la primera, para los hijos de los oficiales de los Cuerpos de la Armada, desde teniente de navío o similar; la segunda, para los hijos de oficiales del Ejército desde teniente coronel efectivo; y la tercera, para todos los demás ${ }^{99}$. Aunque este procedimiento tiene sus precedentes en el siglo XVIII, cuando se recomendaba que tuvieran prioridad los hijos de los oficiales de la Armada y del Ejército, ahora toma rasgos explícitamente corporativos: el factor familiar y profesional se fusionan para asegurar la reproducción de las mismas familias en las Fuerzas Armadas ${ }^{100}$. Además, durante estos años el sentimiento corporativo de algunos cuerpos "suele manifestarse en la concesión de una importancia desmedida a las formas, el protocolo y los signos exteriores de la posición" ${ }^{101}$, y así es como deben interpretarse las pruebas que se le exigen a los aspirantes a guardiamarinas, que comúnmente se han denominado de "limpieza de sangre", y que viene a sustituir a las de nobleza. Éstas se constituían, en primer lugar, de una parte documental, compuesta por las partidas de bautismo y casamiento del pretendiente, padres y cuatro abuelos, a través de la cual se pretende demostrar la legitimidad del joven. También había una prueba testifical que, según el proyecto de 1842, debía hacer constar y acreditar los derechos de ciudadanía del padre y el joven; la profesión, ejercicio o modo de vivir del padre; y "estar considerada la familia del pretendiente por ambas líneas como honrada, sin que sobre ella haya recaído nunca nota que infame o envilezca sus individuos" ${ }^{\prime 102}$. En el texto definitivo de 1844 solo hace referencia a que deben demostrar y "constar ser hijo y nieto de padres honrados, sin que haya nada que pueda empañar su buena reputación y fama por su conducta religiosa y social, y que se les conocen medios para su decorosa subsistencia"103.

El adecuado análisis de este requerimiento es clave ${ }^{104}$. Los expedientes de legitimidad y limpieza de sangre de mitad del siglo XIX son unas pruebas de la buena fama y buena vida, de la distinción, de la honorabilidad, y de la "pertenencia a la primera clase" de las familias. El capital simbólico -y esto es lo más relevante- que

Ibidem, art. 57.

100 Perfecto García, M. A.: "El corporativismo en España: desde los orígenes a la década de 1930", Pasado y memoria: Revista de historia contemporánea, 5 (2006), pp. 185-218.

101 Pro Ruiz, op. cit. (nota 91), p. 457.

102 AMN, Colegio Naval Militar, caj. 448, ms. 1210, op. cit. (nota 93), título segundo, art. 70.

103 Reglamento para el régimen y gobierno del Colegio Naval Militar..., op. cit. (nota 96), art. 51 . El reglamento de 1848 volvió a utilizar la fórmula del proyecto de 1842. Reglamento del Colegio Naval Militar, Madrid, Imprenta de D. Román Matute, 1848.

104 Ortega-Del-Cerro, P.: "Pruebas de distinción en una sociedad en cambio: las informaciones de limpieza de sangre en la Armada (1845-1865)", Historia Social, 85 (2016), pp. 63-82. 
las familias debían demostrar es la honradez. Este concepto se encuentra definido, además de por principios morales y religiosos, por la posición social, la forma de vivir y la profesión o modo de mantenerse económicamente. También se refiere a la fama pública, la distinción del grupo familiar, la capacidad de relación y a los rasgos más inmateriales -aquí es donde muchos aprovechan para dejar mención de su pertenencia a la (antigua) nobleza. El carácter, la naturaleza y los usos de estas pruebas confirman algunas de las ideas de Jesús Cruz, quien afirma que las formas aristocráticas de comportamiento social no estaban en contradicción con el establecimiento de un estilo burgués ${ }^{105}$.

A finales de la década de 1850 parece haber otro movimiento de reforma en los reglamentos de los guardiamarinas y se introducen algunos cambios que vienen a incidir en las tendencias anteriormente descritas ${ }^{106}$. La primera es el examen de acceso, alterando algunas materias. Ahora deberán demostrar sus conocimientos de doctrina cristiana, leer y escribir al dictado, gramática castellana, aritmética razonada y completa según el autor que se señale, traducir correctamente francés o inglés, geografía de España y nociones generales, y principios de dibujo. La segunda es el ahondamiento en ese sistema de listas de los aspirantes a guardiamarinas, coincidiendo con un proceso de cierre de las élites isabelinas ya consagradas a través de un sentimiento de corporativismo ${ }^{107}$. En este caso, una vez dada la merced de aspirante, y antes de proceder al examen de acceso, se establece un sistema de seis listas, cada una de las cuales tiene un cupo determinado: "veintidós por cierto de la totalidad a los hijos de oficiales del Cuerpo General de la Armada, diez ídem a los de los Cuerpos Auxiliares de la misma, catorce ídem a los oficiales de los Cuerpos del Ejército, cuarenta y seis ídem a los de las demás clases de la nación, y ocho ídem supernumerarias y de nombramiento Real para todas las clases indistintamente" 108 . Esto significa que casi la mitad de los futuros guardiamarinas -46\%- serían teóricamente hijos de oficiales militares.

En este nuevo reglamento se incluye igualmente la prueba documental con las partidas de bautismo y casamiento, así como la parte testifical donde se debía corroborar la ciudadanía española del padre y del pretendiente, la profesión o modo de vivir del padre, y la información "que acredite que toda la familia del pretendiente por ambas líneas están tenidas por honradas en concepto público, sin que haya recaído sobre ellas ningún tipo de nota que la infame o envilezca, según leyes vigentes"109. Finalmente, estas pruebas desaparecen en 1865 gracias a la "Ley de supresión de informaciones de limpieza de sangre para establecer matrimonio y para ingresar en carreras del Estado" 110 . Dos años más tarde, en 1867, la entrada de nuevos aspirante se paraliza y en 1868 el Colegio Naval Militar cerrará sus puertas.

Valga exponer, como colofón, las condiciones que serán exigidas a los futuros aspirantes en la Escuela Naval Flotante, cuyo reglamento de 1869 establece en su artículo 1 que para ingresar se necesitaba:

105 Cruz, J.: The Rise of the Middle-Class Culture in Nineteenth-Century Spain, Los Angeles, Louisiana State University Press, Baton Rouge, 2011.

106 Proyecto de reglamento para el Colegio Naval Militar, redactado por la Junta Consultiva de la Armada, en cumplimiento de la Real Orden de 7 de febrero de 1857, 1857, AGMAB, Colegio Naval, leg. 823, s. fol.

107 Pro RuIz, op. cit. (nota 91), p. 449.

108 Reglamento para el régimen, dirección y gobierno del Colegio Naval, Madrid, Imprenta Nacional, 1858.

109 Ibidem, título segundo, artículo 8.

110 Gaceta de Madrid, n $^{\circ}$ 136, Año CCIV, 18 de mayo de 1865, p. 1. 
1. Gozar de los derechos de ciudadano español, 2. Tener más de quince años de edad y menos de diecisiete... 3. Ser de inmejorable robustez y de buena conformación física sin ningún género de imperfección corporal... y 4. Ganar la plaza en pública oposición, en la que se probará el conocimiento complejo de todas las materias que expresa el siguiente programa: aritmética, algebra, geometría, trigonometría... ${ }^{111}$

La sociedad española del ochocientos estuvo atravesada por "una combinación de cambios parciales, con distintos ritmos y contenidos, resistencias materiales y morales, y profundas discontinuidades"112. La reglamentación de la Escuela Naval Flotante destaca por el predominio definitivo de los requisitos personales -que puede considerarse como una expresión de la maduración de esa sociedad burguesa-, por la supresión de cualquier protocolo de distinción familiar y por la desaparición de los mecanismos de cierre social de naturaleza corporativa. Sin embargo, este aparente triunfo en la normativa de un modelo social, construido en base a criterios adquiridos, no puede desligarse del fuerte halo democrático en los años del Sexenio Revolucionario, como tampoco puede olvidarse el peso en las prácticas sociales especialmente en los estratos sociales más altos- de la familia ${ }^{113}$, las relaciones e influencias ${ }^{114}$, o la articulación corporativa y clientelar ${ }^{115}$.

\section{Conclusiones}

El objetivo de este trabajo ha sido indagar sobre una figura -la del cadete navalque no ha sido estudiada suficientemente $\mathrm{y}$, al mismo tiempo, proponerla como un vehículo de análisis de algunas de las transformaciones sociales en España durante los siglos XVIII y XIX. Los requisitos exigidos a los guardiamarinas es una temática sugerente para indagar relacionalmente ambos propósitos, aunque no podemos olvidar que los abordamos desde la normativa, la reglamentación y los discursos. Las conclusiones que podemos extraer deben encuadrarse dentro de una esfera de la realidad social que trata de modelos, de ideas e ideales, de arquetipos sociales, que son a su vez partes fundamentales para el estudio del cambio social.

El guardiamarina nace a principios del setecientos con una fuerte impronta nobiliaria, siendo este el criterio más sobresaliente a lo largo de todo el siglo; sin embargo, es necesario ahondar en esta idea y clarificar la verdadera naturaleza de esta afirmación. La nobleza del cadete naval va intrínsecamente unida al proyecto de servicio que los Borbones irán construyendo a lo largo de la centuria ilustrada. Ade-

111 Reglamento para el ingreso de aspirantes de Marina en la Escuela Naval flotante, y estudios que deberán cursar para ser admitido en dicha escuela y ascender después a Guardia Marina, firmado por Juan Bautista Topete, Madrid, 10 de septiembre de 1869. AGMAB, Colegio Naval, leg. 825, s. fol.

112 Fernández García, A. y Rueda Laffond, J. C.: "La sociedad (1): los grupos sociales", en Fernández GarCÍA, A. (coord.): Los fundamentos de la España liberal (1834-1900): la sociedad, la economía y las formas de vida. Colección Historia de España Menéndez Pidal, tomo XXXIII, Madrid, Espasa Calpe, 1997, p. 102.

113 Carasa Soto, P.: "Presentación. Las familias garantizaron la viabilidad de las élites y la sostenibilidad de los pobres", Historia Contemporánea, 49 (2014), pp. 403-434.

114 Pro RuIz, J.: "Socios, amigos y compadres: camarillas y redes personales en la sociedad liberal", en CHACÓN Jiménez, F. y Hernández Franco, J. (eds.): Familias, poderosos y oligarquías, Murcia, Universidad de Murcia, 2001, pp. 153-173.

115 De la Fuente Monge, G. L.: Los revolucionarios de 1868: élites y poder en la España liberal, Madrid, Marcial Pons, 2000. 
más de reformar las viejas instituciones, o crear otras nuevas, se va erigiendo un nuevo modelo de relación entre el soberano y sus súbditos, a través de un pacto recíproco que alterará las bases fundamentales, aunque no formales, de los estamentos -especialmente el nobiliario- ${ }^{\text {. El objetivo prioritario tras la Guerra de Sucesión }}$ era la atracción de capital humano que pusiese en marcha los nuevos proyectos y que permitiese consolidar la nueva dinastía. La Instrucción de Patiño de 1718 nos muestra la creación de un centro formativo que no solo pretende formar a los futuros oficiales de la Real Armada, sino crear un precedente para los vástagos de la nobleza. Décadas más tarde los objetivos de la Monarquía se dirigen a mejorar la formación de sus servidores, y en la Marina se plasma en el intenso proceso de reforma que pone en marcha el Almirantazgo del infante don Felipe, y que tendrá como resultado más visible las Ordenanzas de 1748. Son en estos años cuando, junto a la nobleza, es necesario atender al "talento" y "aplicación" de los aspirantes.

La segunda mitad del siglo XVIII es clave para entender el proceso de cambio social en España así como la transformación de los guardiamarinas. En este periodo no encontramos una evolución lineal, no se produce un declive de unos rasgos que podríamos considerar simplificadamente adscriptivos y la emergencia de otros nuevos. Se experimenta una amalgama de ideas y discursos que son reveladores para entender esta época. Por un lado, la nobleza, lejos de perder importancia, adquiere una mayor relevancia si atendemos al escrupuloso cuidado con que la Secretaría de Marina decidió controlar este aspecto. Esta nobleza, como se adelanta en la primera mitad de siglo, se encuentra indisolublemente definida por un servicio a la Monarquía que progresivamente se va dignificando y profesionalizando. Por otro lado, los requisitos personales, aunque no se transforman sustancialmente -oficialmente quedan regulados en las Ordenanzas de 1748-, se convierten en un tema con gran protagonismo si observamos los numerosos informes, disposiciones o adicciones que intentan desarrollar y consolidar una mejor instrucción de los cadetes. Por último, también es en este periodo cuando comienza a aparecer explícitamente la capacidad económica como una exigencia a tener en cuenta. El dinero, que era una de las constantes esenciales entre los grupos de poder desde mucho antes, empieza a ser un argumento manifiesto y expreso para negar la plaza -aquí radica el principal elemento de transformación-.

Desde los primeros años del siglo XIX comenzamos a observar las primeras grietas de ese modelo nobiliario de institución a través de voces críticas en la Armada y de proyectos de nuevas reglamentaciones; pero no será hasta 1811 cuando se suprima provisionalmente el aspecto más simbólico -las pruebas de nobleza-, aunque lo realmente interesante es contemplar ese intensísimo clima de debate que durante estos años se genera en torno a esta temática. Estas décadas tan convulsas, pero sobre todo complejas, finalizan con la desarticulación jurídica de la sociedad estamental (1836-1837) y nos colocan frente a una aparente nueva realidad social que se basa en una serie de variables de jerarquización social que, en realidad, estaban en el periodo anterior cubiertas por la dicotómica retórica estamental. El reglamento del Real y Militar Colegio de Caballeros Guardias Marinas (1825) creemos que es la mejor muestra de todo esto. Se propone un guardiamarina noble, sí, y también debía adelantar y dejar por escritura pública que tenían los suficientes recursos económicos para mantenerse, y sin olvidar una prueba de acceso sobre conocimientos básicos en diversas materias que ratificara su adecuación personal. 
El periodo isabelino es especialmente interesante porque permite adentrarnos en una sociedad cuya idiosincrasia se ha minimizado y simplificado. En una jerarquía social que ya no está dividida entre privilegiados y no privilegiados, los criterios de diferenciación aumentan su complejidad. La Armada, en este contexto, siguió aspirando a mantener la supremacía social que tenía en el viejo orden. Los valores nobiliarios, entendidos ahora como un halo de dignidad y preeminencia social, no desaparecen, y de hecho conforme avance el tiempo se conjugarán con una mayor coherencia con una cultura ya consolidada -denominada burguesa-. Los textos de $1842,1844,1848$ y 1858 del Colegio Naval Militar lo ilustran con gran vehemencia. Las condiciones personales adquieren una relevancia que nunca antes habían tenido, y con unos controles bastante exhaustivos. La valía individual del joven era una pieza angular, pero precedida por otros elementos que podemos interpretar como mecanismos de cierre social. La capacidad económica y la profesión o el modo de vivir del padre son los criterios que fijan la línea divisoria entre los que podían ser, o no, aspirantes a guardiamarinas. El sistema de listas de aspirantes muestra el sesgo más corporativo del nuevo modelo, pero sobre todo es necesario atender a las denominadas pruebas de legitimidad y limpieza de sangre. Aunque formalmente son herederas directas de las pruebas de nobleza -comparten la naturaleza, el sistema de testigos, preguntas, etc.--, muestran las variables de jerarquización social propias de este periodo. La distinción social ahora se basa en la fama como concepto público de la familia, de las relaciones y vínculos sociales de la misma, de los espacios que frecuentan y dominan, de la posición y capacidad económica de sus miembros, o de los honores de que pueden hacer gala. El mérito individual, por tanto, comienza a prevalecer, pero nunca desnudo o despojado de un ropaje fundamentalmente familiar y relacional. 